\title{
ESTENOSE HIPERTRÓFICA DE PILORO EM GÊMEAS DIZIGÓTICAS PREMATURAS: RELATO DE CASO
}

\section{HYPERTROPHIC PYLORIC STENOSIS IN PREMATURE DIZYGOTIC TWINS: CASE REPORT}

Ighor Ramon Pallu ${ }^{1}$; Sofia de Souza Boscoli1 ${ }^{1}$; Paula Rubio Vilar ${ }^{2}$; Loraine Entringer Falqueto ${ }^{2}$; Karin Lucilda Schultz ${ }^{1,2}$.

\section{RESUMO}

Introdução: A estenose hipertrófica de piloro infantil (EHPI) consiste num estreitamento do piloro que pode dificultar ou interromper a comunicação entre o duodeno e o estômago do paciente, sendo mais prevalente em lactentes do sexo masculino entre três e oito semanas de vida, com histórico familiar de EHPI. Existem muitas divergências e especulações quanto a etiologia desta doença, e quais genes e fatores ambientais estariam envolvidos no seu desenvolvimento. Relato do caso: Este relato de caso, retrata o diagnóstico e tratamento de EHPI em pacientes gêmeas dizigóticas do sexo feminino, sem histórico familiar, em um Hospital Pediátrico de Referência, de forma a enfatizar a raridade do caso abordado. Conclusão: O quadro clínico, histórico familiar e fatores de risco devem ser explorados amplamente a fim de que se possa realizar um diagnóstico rápido e preciso da doença, evitando quaisquer prejuízos ao desenvolvimento da criança.

Palavras-chave: Estenose Pilórica Hipertrófica. Gêmeos. Piloromiotomia. Pediatria. Procedimentos Cirúrgicos do Sistema Digestório.

\section{ABSTRACT}

Introduction: Hypertrophic infantile pyloric stenosis (IPHP) narrows the pylorus which can hinder or interrupt the communication between the duodenum and the patient's stomach, being more prevalent in male infants between three and eight weeks of age with a family history of IPHP. There are many divergences and speculations about the etiology and which genes would be involved in its development. Case report: This case report portrays the diagnosis and treatment of IPHP in dizygotic twin female patients, without a family history, in a Pediatric Reference Hospital to emphasize the cases rarity. Conclusion: Symptoms, family history, and risk factors must be explored in order to make a quick and accurate diagnosis of the disease, avoiding damage to the child's development.

Keywords: Pyloric Stenosis. Twins. Pyloromyotomy. Pediatrics. Digestive System Surgical Procedures.

\section{INTRODUÇÃO}

A estenose hipertrófica de piloro infantil (EHPI) ocorre devido a hipertrofia progressiva da camada muscular circular pilórica que leva ao estreitamento e alongamento desta região, progredindo na maioria dos casos para obstrução da saída gastrica ${ }^{1}$. A etiologia exata da doença ainda não está bem explicada, porém, estuda-se a possibilidade de fatores genéticos e ambientais estarem envolvidos no processo fisiopatológico ${ }^{3}$. Sabe-se que, em países ocidentais, dois a cada 1.000 nascidos vivos desenvolvem EHPI, sendo mais prevalente em caucasianos, e quatro a cinco vezes mais comum em crianças do sexo masculino ${ }^{1-4}$. Casos de EHPI em gêmeos ou múltiplos são extremamente raros e pouco relatados na literatura ${ }^{5,6}$.

$\mathrm{Na}$ maioria dos pacientes, a doença se manifesta entre a terceira e a oitava semana de vida com a presença de vômitos em jato, não biliosos, geralmente no período pós-prandial $2,4,7,8$. Pode-se notar também, peristaltismo visível em região epigástrica logo após a alimentação e a presença de pequena massa palpável, rígida e móvel, em formato de oliva nesta região $0^{2,4,7,9}$.

No relato a seguir, descrevemos o caso de duas gêmeas dizigóticas e dicoriônicas do sexo feminino, com exames diagnósticos prévios normais pra EHPI e que manifestaram a doença enquanto estavam internadas para investigação de

${ }^{1}$ Faculdades Pequeno Principe, Curso de Medicina - Curitiba - PR - Brasil

${ }^{2}$ Hospital Pequeno Príncipe, Departamento de Cirurgia Pediátrica - Curitiba - PR - Brasil 
outras patologias, sendo necessária a correção cirúrgica para solução do caso.

\section{RELATO DO CASO}

Foram transferidas para hospital pediátrico de referência, duas gêmeas prematuras do sexo feminino, nascidas de parto cesáreo de mãe com idade gestacional de 33 semanas. $O$ peso ao nascer da gêmelar A era de $1855 \mathrm{~g}$ e da gêmelar B de $1845 \mathrm{~g}$. Foram internadas em UTI neonatal com 1 mês e 12 dias de vida para investigação de quadros recorrentes de apneia com necessidade de ventilação com pressão positiva intermitente nasal.

Durante o processo de investigação clínica, não foram encontradas alterações laboratoriais significativas e os exames de imagem realizados apresentavam-se dentro dos padrões de normalidade. Em investigação com otorrinolaringologista, foi realizada nasolaringoscopia em ambas as pacientes, resultando no diagnóstico de laringomalácia nas gemelares A e B. Foi necessária intervenção cirúrgica na gemelar $\mathrm{B}$, aos 2 meses e 11 dias de vida, enquanto a gêmelar $A$ foi mantida em observação para posterior reavaliação do caso. Quatro dias após o procedimento, a gêmelar $B$ iniciou com quadro recorrente de vômitos não-biliosos pós-prandiais, sendo realizada uma nova ultrassonografia (US) abdominal total para investigação. Ao realizar o exame, foi diagnosticado o quadro de EHPI, cujo piloro apresentava dimensões aumentadas: comprimento de $16,8 \mathrm{~mm}$ e espessura da parede muscular de 3,6mm (Figura 1A). A cirurgia corretiva foi realizada no dia seguinte ao diagnóstico.
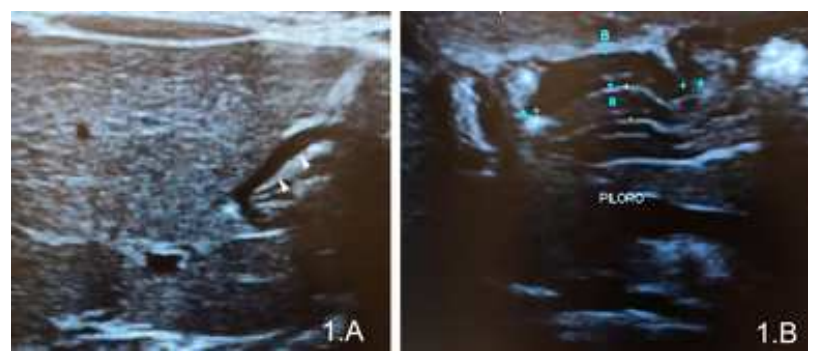

Figura 1. A. Exame de ultrassonografia abdominal normal de gemelar $\mathrm{B}$, com duodeno em comprimento e espessura habituais indicado pelas setas brancas. B. Ultrassonografia com diagnóstico de EHPI em gemelar B (Comprimento entre os pontos A é de $16,8 \mathrm{~mm}$; Espessura entre os pontos B é de $3,6 \mathrm{~mm})$.
Devido o quadro de EHPI da irmã, foi realizado US abdominal total na gemelar A, a qual apresentava o piloro com dimensões habituais (espessura $<2 \mathrm{~mm}$ e comprimento $<14 \mathrm{~mm}$ ). Quatro dias após a realização da última US abdominal, a gêmea $A$ apresentou quadro semelhante ao da irmã com vômitos não-biliosos pós-prandiais. Em nova US abdominal realizada a beira do leito, foi diagnosticado EHPI com o piloro alongado de $16 \mathrm{~mm}$ e parede muscular espessada de 2,5mm, sendo também necessária a realização de piloromiotomia de Fredet-Ramstedt.

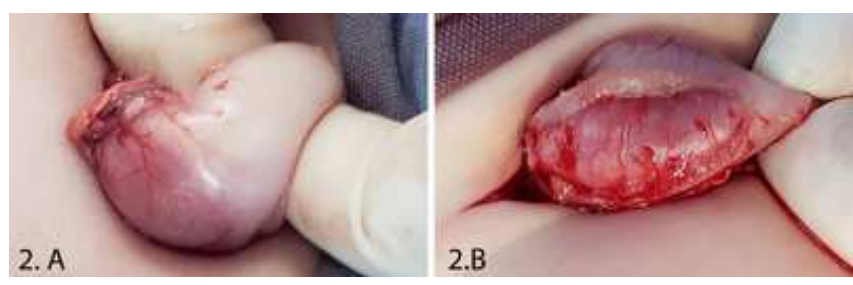

Figura 2. A. Músculo pilórico hipertrófico. B. Pilorotomia descrita por Fredet-Ramstedt. Excisão longitudinal da camada extramucosa da musculatura pilórica sem realização de sutura.

O pós-operatório de ambas transcorreu sem intercorrências e a dieta foi reestabelecida completamente em cerca de dois dias, sem novos episódios de vômitos. As irmãs permaneceram internadas aos cuidados da pediatria por outros motivos clínicos.

\section{DISCUSSÃO}

$\mathrm{O}$ grande número de teorias e hipóteses sobre a origem e fisiopatologia da EHPI provam que ainda há muito o que se pesquisar e descobrir sobre a doença ${ }^{3,7}$. Estudos ao redor do mundo têm mostrado que fatores genéticos tem papel fundamental na etiologia multifatorial da EHPI 1-3,9. O risco de desenvolvimento da doença em gêmeos monozigóticos é 200 vezes maior do que na população geral e a agregação familiar da estenose de piloro pode ser observada por varias gerações, tanto na família materna como na paterna $1,3,5,10$. Além disso, a prevalência até cinco vezes maior no sexo masculino e a manifestação da doença em ambos os gêmeos reforçam a influência genética da EHPI $1,2,5,6,8$. No caso relatado acima, além da incomum manifestação em crianças do sexo feminino e da ausência de histórico 
familiar compativel, as gêmeas em questão são dizigóticas.

Em gêmeos monozigóticos, em cerca de $50 \%$ dos casos não há manifestação da doença em ambas as crianças. Porém, sabe-se que, a taxa de concordância de EHPI em gêmeos dizigótios é consideravelmente mais baixa do que em gêmeos monozigóticos, o que torna o caso acima ainda mais raro ${ }^{2,5,10 .}$

Alguns estudos têm demonstrado que fatores perinatais também influenciam na patogênese da EHPI. A alimentação neste periodo de desenvolvimento tem mostrado grande influência no desenvolvimento da doença. Observou-se, que a alimentação com fórmula aumentou em quase 2,5 vezes o risco de desenvolvimento da EHPI (OR=2,46, IC 95\%: 1,76-3,43) em comparação com crianças em amamentação exclusiva ${ }^{9,11,12}$.

Além disso, uma revisão sistemática concluiu que crianças nascidas de parto cesáreo tem risco aumentado para o desenvolvimento da EHPI $(\mathrm{OR}=1,63$, IC 95\%: 1,53-1,73), bem como, a prematuridade também eleva o risco para a doença $\left(\mathrm{OR}=1,37\right.$, IC de 95\%: 1,12-1,67) ${ }^{9}$. Devido as circunstâncias da gestação, foi necessária a realização de parto cirúrgico das gêmeas com 33 semanas de idade gestacional, ficando as mesmas expostas aos fatores ambientais acima citados.

\section{CONCLUSÃO}

Devido raridade e a etiologia multifatorial da EHPI, é importante levar em conta não somente o quadro clínico, mas também todo o histórico familiar do paciente, e os fatores ambientais e de risco aos quais o mesmo possa ter sido exposto. Desta forma, é possivel corrigir o problema de maneira mais precisa e imediata evitando quaisquer prejuízos para o desenvolvimento da criança.

\section{REFERÊNCIAS}

1. Peeters B, Benninga, MA, Hennekam RCM. Infantile hypertrophic pyloric stenosis-genetics and syndromes. Nat Rev Gastroenterol Hepatol. 2012;9(11):646-60.

doi: $10.1038 /$ nrgastro.2012.133.

2. Yang G, Brisseau G, Yanchar NL. Infantile hypertrophic pyloric stenosis: An association in twins? Paediatr Child Health. 2008;13(5):383-5. doi: $10.1093 / \mathrm{pch} / 13.5 .383$.

3. Rogers IM. The cause of pyloric stenosis of infancy: A hyperacidity pathogenesis. Med Hypotheses. 2020;141:108116.

doi: 10.1016/j.mehy.2015.11.023.

4. Hsu P, Klimek J, Nanan R. Infantile hypertrophic pyloric stenosis: Does size really matter? J Paediatr Child Health. 2014;50(10):827-8.

doi: $10.1111 /$ j.1440-1754.2010.01778.x.

5. Gezer $\mathrm{H}$, et al. Hypertrophic pyloric stenosis in twins; genetic or environmental factors. Clin Genet. 2015;87(4):388-91.

doi: $10.1111 /$ cge. 12399 .

6. Baker D, et al. Infantile hypertrophic pyloric stenosis in monozygotic twins: a case report and review of genetic and modifiable risk factors. Ann Ped Surg. $\quad 2018 ; 14(3): 182-6$. doi:10.1097/01.XPS.0000535044.678 56.29 .

7. Szmytkowska K. Congenital hypertrophic pyloric stenosis in twins. Med Sci Monit. 2000;6(6):1179-81.

8. Kapoor R, et al. Prevalence and descriptive epidemiology of infantile hypertrophic pyloric stenosis in the United States: A multistate, population-based retrospective study, 19992010. Birth Defects Res. 2019;111(3):159-69.

doi: $10.1002 /$ bdr2.1439.

9. Zhu J, et al. Perinatal risk factors for infantile hypertrophic pyloric stenosis: a meta-analysis. J Pediatr Surg. 2017;52(9):1389-97.

doi: 10.1016/j.jpedsurg.2017.02.017.

10. Krogh C, et al. Familial aggregation and heritability of pyloric stenosis. JAMA. 2010;303(23):2393-9.

doi: $10.1001 /$ jama.2010.784.

11. Marchini G, Simoni MR, Bartolini F, et al. Plasma gastrin and somatostatin levels in newborn infants receiving supplementary formula feeding. Acta Paediatr 1994; 83(4):374-7. doi: 10.1111/j.1651-2227.1994.tb18122.x.

12. Almeida $\mathrm{M}$, et al. Análise da osmolalidade do leite humano e da fórmula infantil com a viscosidade modificada para uso em lactentes com disfagia. Rev. CEFAC. 2018;20(6):770$7 . \quad$ doi: 10.1590/1982021620182064218. 
Pallu et al.

Estenose hipertrófica de piloro em gêmeas dizigóticas prematuras: Relato de caso

Fonte de financiamento: Não

Conflito de interesses: Não

Data de Submissão: 20 Abril 2021

Decisão final: 26 Setembro 2021

\section{Autor de Correspondência:}

Karin Lucilda Schultz

E-mail: karinschultz@yahoo.com 